\title{
Diagnosing dementia and normal aging: clinical relevance of brain ratios and cognitive performance in a Brazilian sample
}

M.L.F. Chaves ${ }^{1,2}$, D. Ilha3, A.L.G. Maia ${ }^{1}$, E. Motta ${ }^{1}$, R. Lehmen ${ }^{1}$ and L.M. Oliveira ${ }^{1}$

\author{
1Programa de Ciências do Comportamento, \\ Curso de Pós-Graduação em Medicina, Clínica M édica, \\ ${ }^{2}$ Serviços de Neurologia and ${ }^{3}$ Radiologia, \\ Departamento de Medicina Interna, Hospital de Clínicas de Porto Alegre, \\ Universidade Federal do Rio Grande do Sul, Porto Alegre, RS, Brasil
}

\section{Correspondence \\ M.L.F. Chaves \\ Serviço de Neurologia \\ Hospital de Clínicas de Porto Alegre \\ R. Ramiro Barcelos, 2350, Sala 2040 \\ 90035-003 Porto Alegre, RS \\ Brasil \\ Fax: + 55-51-311-4684 \\ E-mail: mchaves@vanet.com.br}

Received O ctober 22, 1998

Accepted June 18, 1999

\section{Abstract}

The main objective of the present study was to evaluate the diagnostic value (clinical application) of brain measures and cognitive function. Alzheimer and multiinfarct patients $(\mathrm{N}=30)$ and normal subjects over the age of $50(\mathrm{~N}=40)$ were submitted to a medical, neurological and cognitive investigation. The cognitive tests applied were Mini-Mental, word span, digit span, logical memory, spatial recognition span, Boston naming test, praxis, and calculation tests. The brain ratios calculated were the ventricle-brain, bifrontal, bicaudate, third ventricle, and suprasellar cistern measures. These data were obtained from a brain computer tomography scan, and the cutoff values from receiver operating characteristic curves. We analyzed the diagnostic parameters provided by these ratios and compared them to those obtained by cognitive evaluation. The sensitivity and specificity of cognitive tests were higher than brain measures, although dementia patients presented higher ratios, showing poorer cognitive performances than normal individuals. Normal controls over the age of 70 presented higher measures than younger groups, but similar cognitive performance. We found diffuse losses of tissue from the central nervous system related to distribution of cerebrospinal fluid in dementia patients. The likelihood of case identification by functional impairment was higher than when changes of the structure of the central nervous system were used. Cognitive evaluation still seems to be the best method to screen individuals from the community, especially for developing countries, where the cost of brain imaging precludes its use for screening and initial assessment of dementia.

\section{Introduction}

In 1942, Evans (1) developed a ratio of linear measures to quantify the amount of ventricular enlargement in the pneumoencephalogram. With the advent of computer tomography scanning (CT) and magnetic
Key words

- Brain ratios

- Aging

- Dementia

- Cognition resonance imaging (MRI), several similar measures were developed. The most commonly used ones are the intercaudate distance (CC), the bifrontal distance $(\mathrm{FH})$, and some estimates of brain width to correct for overall brain size.

Many studies have explored differences 
in the bicaudate and bifrontal measures between various patient groups and normal controls. Some investigators studied the effects of aging on the volume of the basal ganglia in individuals with Down syndrome (DS) and the relationship between basal ganglion volumes, neuropsychological test performance, and dementia status. DS subjects showed larger putamen volumes despite significantly smaller total brain volumes. The association between neuropsychological test performance and dementia status in the DS subjects appeared to be a reflection of neurodevelopmental or atrophic reductions in overall brain volume rather than a reflection of specific basal ganglion abnormality. The results suggested that volume reductions of the basal ganglia are not a salient feature of aging or of the dementia associated with DS (2).

Clinical and neuropathological evaluation of elderly subjects with dementia has been traditionally based on focal signs of brain disease. The clinical observation of severe memory impairment in patients with Alzheimer's disease and localization of senile plaque and neurofibrillary tangle formations in hippocampi implicate focal temporal lobe pathology and help to explain severe memory dysfunction (3). The suprasellar cistern (SSC), an area at the base of the brain, is assumed to reflect the integrity of its surrounding structures, which include the amygdala, hippocampus, entorhinal cortex, orbital and straight gyri of the frontal lobe, pons and midbrain. Measures of the SSC may reflect the extent of atrophy in the structures that surround it, primarily in the medial temporal lobes (3) and possibly in basal forebrain and brainstem structures.

The application of brain measure ratios depends on appropriate rater training and knowledge of the normal variability of the population under study. Although these ratios are used to enhance diagnostic accuracy, the lack of adequate diagnostic evaluations of this method makes it uncertain. Develop- ing countries should invest in procedures like this only after all aspects of their use have been properly defined and shown to be relevant especially in terms of clinical application.

Variables other than diseases, such as age, nutrition, socioeconomic conditions (education), and environmental characteristics (rural and urban area), may produce significant ratio differences among groups of the same population (4).

The main purpose of the present study was to investigate the diagnostic value of brain ratios (sensitivity and specificity) and compare it to neuropsychological evaluation. Cerebral ratios from CT scans, as well as cognitive function, were obtained from dementia patients and normal aged subjects to detect and quantify the influence of aging and dementia in a Brazilian sample. Sex, educational level, age, socioeconomic and health conditions were recorded to analyze their relations to brain structure and function.

\section{Subjects and Methods}

The patient group was composed of 30 subjects, 17 Alzheimer's disease ( 8 males, 9 females; age range, 54 to 89 years) and 13 multiinfarct ( 7 males, 6 females; age range, 50 to 74 years) from the Dementia Outpatient Clinic of Hospital de Clínicas de Porto Alegre. The diagnostic criteria for Alzheimer's disease were those of the National Institute of Neurological and Communicative Disorders and Stroke (5), and the criteria for vascular dementia (multiinfarct) classification were those of NINDS-AIREN (6), Gustafson (7) and the Hachinski ischemic score (8). All patients had a mild degree of dementia according to the Blessed scale (9) (scores of less than 10). The complete evaluation of cases followed a standard protocol used in this clinic (10), where CT scans are part of the investigation.

The normal group consisted of 40 com- 
munity subjects ( 19 males, 21 females, mean age 65 years, range 51 to 90) without any chronic, neurologic or psychiatric symptoms. They answered a call for healthy subjects over the age of 50 for the present study. The subjects were submitted to a standardized interview (11) and examination for the determination of their medical, neurological and psychiatric conditions. Subjects selected after complete evaluation were submitted to a CT scan without administration of intravenous contrast (12).

The sample was divided into three groups according to age for the analysis of normal aging. Group 1 consisted of 15 subjects 50 to 60 years old, group 2 , of 13 subjects 61 to 70 years old, and group 3, of 12 subjects 71 to 90 years old. Research assistants performed the neurological and physical examination of all participants. Fourteen percent of dementia patients presented normal neurological examination, $43 \%$ soft signs, $7 \%$ localized deficit and 29\% diffuse, severe abnormalities. Volunteers had normal neurological performances. The physical examination did not reveal abnormalities in any of the participants (dementia and controls). All patients and normal controls were right handed.

A battery of memory, language, visuospatial abilities, calculation, abstraction, praxis and gnosis tests $(10,13)$ were applied to assess cognition, with the Mini-Mental state examination included (14). Copying the pictures of a house and a clock (15) was used to evaluate visuo-constructional abilities. We applied an adapted version of the Boston naming test (16) to check this language function. The spatial recognition span test (17) was used to test visual memory span. Mini-Mental scores were used to evaluate the severity of cognitive deficit. Moderate impairment scores were from 10 to 17 , and severe from zero to 10 (14).

We applied the Bronfman scale (18) for classification of sociocultural status. This scale was developed for epidemiological research in Brazil, and was based on the indi- vidual/family salary (minimum wages), type of activity (entrepreneurs, liberal professionals, employees, etc.), and house conditions (light and sewage), among other socioeconomic parameters. Classes may range from lower low to upper high, representing 9 different groups. Subjects belonged to the upper low (uL), lower, middle and upper middle ( $\mathrm{M}, \mathrm{M}, \mathrm{uM}$ ) classes, indicating the middle to low social background origin of the sample, similar to the general population of the area. Dementia patients were distributed as follows: uL, $12 \%$; $1 \mathrm{M}, 35 \%$; M, 35\%, and uM, $19 \%$. Frequencies among normal controls were: uL, $16 \%$; $1 \mathrm{M}, 43 \%$; M, 27\%, and uM, $14 \%$. Normal volunteers grouped by age were distributed as follows: age 1: uL, 27\%; $1 \mathrm{M}, 27 \%$; M, 33\%, and $\mathrm{uM}, 13 \%$. Age $2: 1 \mathrm{M}$, $39 \%$; M, 39\%, and uM, 23\%. Age 3: uL, $22 \%$, and $1 \mathrm{M}, 78 \%$.

The Committee for the Ethics in Research of Hospital de Clínicas de Porto Alegre approved the research project and all participants gave signed consent after the nature of the procedures had been fully explained.

Brain ratios were determined from CT scans using a standard technique $(12,19,20)$ by measuring distances and areas of some regions of interest adjusted to brain size. The measures used were the ventricle-brain ( $\mathrm{VBr}$ ), bicaudate (BCr), bifrontal (BFr), suprasellar cistern ( $\mathrm{SSCr}$ ), and third-ventricle (IIIVr) ratios. $\mathrm{BCr}$ is $\mathrm{CC}$ divided by the distance between the inner tables of the skull at $\mathrm{CC}$, and BFr is FH divided by the distance between the inner table of the skull at the $\mathrm{FH}$ line (21-26). SSCr is the area of the suprasellar cistern divided by the brain area (at the level of frontal horns) $(19,27)$. $\mathrm{VBr}$ was obtained by dividing the lateral ventricle area by the brain area (at the same level) (28).

The CT scans (without contrast) were obtained with a clinical scanner (Siemens, São Paulo, SP, Brazil, Somatom DR). The CT density number scale was -1000 Hounsfield units for air and zero for water. 
The scans were obtained approximately $15^{\circ}$ to the canthomeatal line starting at the level of the chiasmatic cistern and proceeding to the level of the superficial sulci at the vertex. We obtained approximately 12 slices per subject ( $8 \mathrm{~mm}$ thick). The radiologist who performed the exams was blind to diagnosis of subjects.

Data were analyzed statistically by the Student $t$-test for independent samples, oneway ANOVA followed by the Tukey test and MANOVA with covariance and multivariate procedures $(29,30)$. All variables were submitted to a pegboard test (normal probability plot) before being analyzed by MANOVA (30). MANOVA coefficients (reverse Helmert) were used for the identification of differences (a positive coefficient expresses greater mean among the class factor of higher order). Sensitivity and specificity analysis of brain ratios, as well as the Mantel-Haenszel chi-square test (Yates corrected and exact confidence limits due to the small size of the sample) were applied to patients with dementia and aging patients $(31,32)$. Cutoff points for brain ratios were obtained by analysis of Gaussian distributions for multiples of the median (the observed measure was divided by the expected value, controlled for age) and receiver operating characteristic curves (33).

\section{Results}

Table 1 shows the analyses of brain ratios controlled for the age effect for dementia and normal controls. All but SSCr were higher in dementia patients. Bi-caudate, bifrontal and ventricle-brain ratios presented salient magnitudes among dementia subjects, but not among normal individuals, suggesting more diffuse, telencephalic and diencephalic losses of tissue from the CNS of dementia patients.

Brain ratios from Alzheimer and vascular patients were not significantly different (MANOVA, age controlled). Covariance a- nalysis showed significant regression of $\mathrm{VBr}$ $(\mathrm{B}=0.177$, beta $=0.427, \mathrm{P}=0.001), \operatorname{IIIVr}(\mathrm{B}$ $=0.018$, beta $=0.458, \mathrm{P}=0.000), \operatorname{SSCr}(\mathrm{B}=$ 0.034 , beta $=0.326, \mathrm{P}=0.011)$, and $\mathrm{BCr}(\mathrm{B}$ $=0.225$, beta $=0.555, \mathrm{P}=0.000$ ) with age.

Performances in the Mini-Mental test were different between groups, and were impaired in dementia patients (Alzheimer and vascular). The range of scores within the dementia groups suggested moderate to severe levels of impairment (34). Alzheimer patients presented lower scores than multiinfarct patients. The analysis of cognitive performance between subgroups of patients defined by Mini-Mental cutoffs demonstrated significantly lower performance for digit span, famous faces, visual recognition, naming, abstraction and calculation among severely impaired patients than among moderately impaired patients, regardless of diagnosis (MANOVA, $\mathrm{P}<0.05$ ).

Age, educational level (one-way ANOVA followed by the Tukey test, $\mathrm{P}>0.05$ ) and social conditions (Mantel-Haenszel chisquare with Yates correction, $\mathrm{P}>0.05$ ) were similar for all groups.

Brain ratios were compared among normal aging subjects (Table 2). The $\mathrm{BCr}$ was significantly different among the 3 groups, with the oldest, group 3, having higher dimensions than group 2, which had higher dimensions than group 1. Age group 3 (older subjects) presented higher third ventricle and suprasellar ratios than groups 1 and 2, while no differences were observed between the latter two groups in these measures. $\mathrm{VBr}$ and $\mathrm{BFr}$ were similar for all age groups.

The suprasellar cistern ratio did not differ between dementia and controls, or among age groups and dementia patients (as the fourth class of factor) by a multivariate MANOVA (Table 3).

No difference was found in brain measures analyzed on the basis of health conditions (MANOVA, $\mathrm{P}>0.05$ ) controlled for age. Social conditions, tested by recoding the four social classes of the sample into two 
$(1=$ upper low and lower middle; $2=$ middle and upper middle), showed a significant effect on $\mathrm{SSCr}(\mathrm{F}=4.51203 ; \mathrm{P}=0.038$; coefficient $=0.370767)$, while $\mathrm{VBr}$, IIIVr, BFr, and $\mathrm{BCr} \operatorname{did} \operatorname{not}(\mathrm{F}=1.53198, \mathrm{P}=0.219 ; \mathrm{F}=$ $0.15887, \mathrm{P}=0.692 ; \mathrm{F}=1.10917, \mathrm{P}=0.297$; $\mathrm{F}=0.45959, \mathrm{P}=0.501$, respectively). We did not observe any further effect of age or social conditions on brain ratios (VBr: $\mathrm{F}=$ 1.67192, $\mathrm{P}=0.184$; IIIVr: $\mathrm{F}=1.36200, \mathrm{P}=$ 0.264; SSCr: $F=0.51732, P=0.672 ; B F r: F$ $=1.04661, \mathrm{P}=0.380 ; \mathrm{BCr}: \mathrm{F}=0.78754, \mathrm{P}=$ 0.506 ).

The scores for the Mini-Mental test were

Table 1 - Brain ratios obtained for dementia patients and normal controls (MANOVA F-values, coefficients of the two-level factor comparison, and $\mathrm{P}$ value).

Results are reported as means $\pm \mathrm{SD}$. VBr: Ventricle brain ratio; $\mathrm{BFr}$ : bifrontal ratio; $\mathrm{BCr}$ : bicaudate ratio; IIIVr: third ventricle ratio; SSCr: suprasellar cistern ratio.

\begin{tabular}{lccccc}
\hline Ratios & Dementia (Group 1) & Controls (Group 2) & F & Coefficient level 1 & P value \\
\hline $\mathrm{VBr}$ & $12.28 \pm 4.9$ & $9.78 \pm 3.2$ & 8.37494 & -2.8042599 & 0.005 \\
$\mathrm{BFr}$ & $35.85 \pm 4.7$ & $31.93 \pm 4.1$ & 15.88289 & -4.4328615 & 0.000 \\
$\mathrm{BCr}$ & $16.67 \pm 4.6$ & $13.45 \pm 3.4$ & 16.37103 & -3.5336548 & 0.000 \\
$\mathrm{IIIVr}$ & $1.01 \pm 0.5$ & $0.80 \pm 0.3$ & 6.36013 & -0.23139952 & 0.014 \\
$\mathrm{SSCr}$ & $4.96 \pm 1.2$ & $4.68 \pm 0.8$ & 1.93819 & -0.35419506 & 0.169
\end{tabular}

Table 2 - Brain ratios obtained for normal controls: age groups (MANOVA multivariate F-values, coefficients of each two-level factor comparison with significance, and $P$ value for the 3 levels).

Results are reported as means \pm SD. Age 1: 50-60 years; age 2: 61-70 years; age 3: 71-90 years; $V B r$ : ventricle brain ratio; BFr: bifrontal ratio; $\mathrm{BCr}$ : bicaudate ratio; IIIVr: third ventricle ratio; level 1: comparison between age 1 and age 2; level 2: comparison between age 3 and ages 1 and 2 .

\begin{tabular}{|c|c|c|c|c|c|c|c|}
\hline \multirow[t]{2}{*}{ Variable } & \multirow[t]{2}{*}{ Age 1} & \multirow[t]{2}{*}{ Age 2} & \multirow[t]{2}{*}{ Age 3} & \multirow[t]{2}{*}{$F$} & \multicolumn{2}{|c|}{ Coefficient } & \multirow[t]{2}{*}{$P$ value } \\
\hline & & & & & Level 1 & Level 2 & \\
\hline $\mathrm{VBr}$ & $8.63 \pm 2.40$ & $9.46 \pm 2.66$ & $11.49 \pm 4.81$ & 2.22333 & $0.3747(0.773)$ & $2.5376(0.049)$ & 0.124 \\
\hline $\mathrm{BFr}$ & $30.98 \pm 4.08$ & $31.17 \pm 4.64$ & $34.05 \pm 4.29$ & 1.70060 & $-0.0319(0.076)$ & $2.9593(0.985)$ & 0.198 \\
\hline $\mathrm{BCr}$ & $11.01 \pm 2.46$ & $14.64 \pm 2.25$ & $15.62 \pm 4.60$ & 6.80377 & $2.8602(0.024)$ & $2.9947(0.015)$ & 0.003 \\
\hline $\mathrm{IIIVr}$ & $0.66 \pm 0.18$ & $0.78 \pm 0.30$ & $1.07 \pm 0.46$ & 5.28714 & $0.1131(0.364)$ & $0.3558(0.005)$ & 0.010 \\
\hline
\end{tabular}

Table 3 - Suprasellar cistern ratios (SSCr) for the dementia and age groups of normal controls (MANOVA multivariate F-values, coefficients of each two-level factor comparison with significance and $\mathrm{P}$ value of the 3 levels).

Results are reported as means \pm SD. Age $1=50$ to 60 years; Age $2=61$ to 70 years; Age $3=71$ to 90 years; SSCr: suprasellar cistern ratio; level 1: comparison between age groups 1 and 2; level 2: comparison between age group 3 and groups 1 and 2; level 3: comparison between dementia group and age groups 1, 2 and 3 .

\begin{tabular}{|c|c|c|c|c|c|c|c|c|c|}
\hline \multirow{2}{*}{\multicolumn{2}{|c|}{ Age 1}} & \multirow[t]{2}{*}{ Age 2} & \multirow[t]{2}{*}{ Age 3} & \multirow[t]{2}{*}{ Dementia } & \multirow[t]{2}{*}{$\mathrm{F}$} & \multicolumn{3}{|c|}{ Coefficient } & \multirow[t]{2}{*}{$P$ value } \\
\hline & & & & & & Level 1 & Level 2 & Level 3 & \\
\hline $\mathrm{SSCr}$ & $4.31 \pm 0.71$ & $4.69 \pm 0.69$ & $5.25 \pm 0.95$ & $4.96 \pm 1.23$ & 2.225 & $\begin{array}{c}0.3798 \\
(0.318)\end{array}$ & $\begin{array}{c}0.753 \\
(0.053)\end{array}$ & $\begin{array}{c}0.248 \\
(0.340)\end{array}$ & 0.095 \\
\hline
\end{tabular}


similar for age groups 1,2 , and 3 of normal controls, but were significantly lower among dementia patients (Alzheimer and vascular). Complete cognitive evaluation showed no significant differences between age groups. This indicates normal cognitive function independent of changes in brain size produced by aging.

Neuropsychological evaluation showed marked differences in all cognitive tests between dementia and normal controls by MANOVA controlled for age and education. Dementia patients presented lower scores in the cognitive tests. Comparisons between the Alzheimer and multiinfarct groups demonstrated (Table 4) significantly lower test performances for the first group.

Covariance analysis showed significant regressions between years of schooling and Mini-Mental state examination ( $\mathrm{B}=0.389$, beta $=0.336, \mathrm{P}=0.010)$ and calculation $(\mathrm{B}=$ 0.091 , beta $=0.259, \mathrm{P}=0.043)$. Age was correlated with digit $\operatorname{span}(\mathrm{B}=-0.054$, beta $=$ $-0.281, \mathrm{P}=0.036)$, word span $(\mathrm{B}=-0.050$, beta $=-0.325, \mathrm{P}=0.015)$, calculation $(\mathrm{B}=$ -0.052 , beta $=-0.341, P=0.009)$, copy of the house $(\mathrm{B}=-0.023$, beta $=-0.291, \mathrm{P}=0.031)$, and copy of the clock $(\mathrm{B}=-0.032$, beta $=$
$-0.374, \mathrm{P}=0.005)$. The other tests did not present significant regressions for age and/ or schooling.

\section{Diagnostic value of ratios and neuropsychological evaluation}

Cutoff values for brain ratios obtained by Gaussian distribution of multiples of the median were: 1) $\mathrm{VBr}: 12.00,2) \mathrm{BCr}: 15.00$, 3) BFr: 34.00, 4) IIIVr: 1.00, and 5) SSCr: 5.00 .

The sensitivity and specificity of the ratios are shown in Table 5. The sensitivity of the brain ratios was low for all measures, although specificity was higher. This was observed especially when dementia patients were compared to control age group 1 (younger individuals) (Table 6).

We evaluated the correlation of the diagnosis of dementia with the brain ratios by the Mantel-Haenszel chi-square test with Yates correction. Each brain measure was tested individually and was followed by stepwise analysis (32) (Table 7). Individual analysis presented higher associations between $\mathrm{BCr}$, $\mathrm{BFr}$ and IIIVr with the diagnosis of dementia, and the stepwise analysis showed an

Table 4 - Results of the neuropsychological evaluation (Alzheimer, multiinfarct and normal volunteers) reported as mean \pm standard deviation (controlled for age and years of education) (MANOVA F-values, coefficients of the two-level factor comparison, and $\mathrm{P}$ value).

Coeff = Coefficient; DS = digit span; MM = M ini-Mental; WS = word span; FF = famous faces; SRS = spatial recognition span; Calc = calculation; Abst = abstraction; Ideom = ideomotor. *Comparison between Alzheimer and multiinfarct patients; ** comparison between dementia (Alzheimer and multiinfarct together) and normal controls.

\begin{tabular}{|c|c|c|c|c|c|c|c|c|c|}
\hline \multirow[t]{2}{*}{ Tests } & Alzheimer & Multi-infarct & Control & $\mathrm{F}^{*}$ & Coeff* & P value* & $\mathrm{F}^{* *}$ & Coeff** & $\mathrm{P}$ value** \\
\hline & (Group 1) & (Group 2) & (Group 3) & & & & & & \\
\hline DS & $2.44 \pm 1.99$ & $4.50 \pm 2.07$ & $7.16 \pm 1.88$ & 4.4375 & 1.7593 & 0.047 & 50.8648 & 3.8585 & 0.000 \\
\hline MM & $9.44 \pm 7.02$ & $18.90 \pm 6.85$ & $27.76 \pm 3.00$ & 9.2672 & 7.9335 & 0.006 & 80.5013 & 13.5946 & 0.000 \\
\hline WS & $2.25 \pm 1.48$ & $3.80 \pm 1.93$ & $6.32 \pm 1.45$ & 4.0629 & 1.4468 & 0.056 & 59.7205 & 3.8585 & 0.000 \\
\hline $\mathrm{FF}$ & $6.19 \pm 3.87$ & $10.50 \pm 4.50$ & $18.54 \pm 2.04$ & 4.8944 & 3.8546 & 0.038 & 129.741 & 10.4922 & 0.000 \\
\hline SRS & $3.13 \pm 2.58$ & $6.90 \pm 3.14$ & $10.24 \pm 2.95$ & 8.2962 & 3.2396 & 0.009 & 38.6161 & 5.1544 & 0.000 \\
\hline Calc & $1.56 \pm 1.03$ & $2.50 \pm 0.71$ & $3.68 \pm 0.67$ & 7.7087 & 1.8590 & 0.011 & 56.9089 & 1.6959 & 0.000 \\
\hline Abst & $1.87 \pm 1.09$ & $2.50 \pm 0.85$ & $4.95 \pm 0.23$ & 8.1606 & 1.5052 & 0.009 & 85.7379 & 2.2009 & 0.000 \\
\hline Naming & $12.69 \pm 6.99$ & $19.40 \pm 6.43$ & $24.57 \pm 0.60$ & 4.3546 & 5.9908 & 0.049 & 43.8675 & 8.9049 & 0.000 \\
\hline House & $1.94 \pm 1.69$ & $4.20 \pm 1.81$ & $8.32 \pm 1.33$ & 4.5282 & 0.7562 & 0.045 & 144.967 & 5.1777 & 0.000 \\
\hline Clock & $0.75 \pm 1.00$ & $2.40 \pm 1.58$ & $3.00 \pm 0.00$ & 3.1156 & 0.8332 & 0.091 & 14.1772 & 0.8723 & 0.000 \\
\hline Ideom & $2.25 \pm 1.29$ & $3.40 \pm 1.27$ & $5.00 \pm 0.00$ & 1.3782 & 0.4899 & 0.253 & 53.9902 & 3.546 & 0.000 \\
\hline
\end{tabular}


increase of association with dementia, with an odds ratio of 6.30 (Mantel-Haenszel odds ratio, with exact confidence limits).

We used the same technique to analyze the association of cognitive performance with dementia, whose cutoffs were previously studied for detection of dementia produced by organic diseases (i.e., Alzheimer, vascular, Parkinson, etc.) (11). We applied a multiple parallel strategy for test positivity $(50 \%$ +1 tests should be positive, i.e., below cutoff) to identify positive individuals for $\operatorname{cog}$ nitive deficit $(11,35)$. The association observed by this method was higher, as also was the odds ratio (Table 7). The sensitivity of cognitive performance was $87 \%$ and the specificity $98 \%$.

To increase the effectiveness of the parallel strategy we mixed cognitive tests and brain ratios; however, sensitivity, specificity and odds ratio were lower than cognitive tests alone (Table 7). Sensitivity was $76 \%$ and specificity $90 \%$.

\section{Discussion}

CT and MRI, which are currently the most commonly used imaging techniques, provide optimal visualization of brain images. CT and especially MRI should recognize and differentiate the changes seen in normal aging from pathological brain anomalies. However, those demonstrated by CT and MRI in the most commonly encountered types of dementia are still poorly specific and never pathognomonic. Some authors have suggested that $\mathrm{CT}$ and MRI should be promptly performed in demented patients in order to rule out diseases curable by surgery, which CT and MRI demonstrate particularly well (36), although they infrequently cause dementia.

The present results suggest diffuse losses of CNS tissue, especially related to the distribution of cerebrospinal fluid (CSF) in dementia patients. Ratios were higher in dementia patients, except for the suprasellar cistern. The suprasellar cistern ratio is an expression of mesial temporal lobe at the level of the amygdala and entorhinal cortex $(27,37)$. The similarities observed between the age and dementia groups suggest that

Table 5 - Sensitivity and specificity of brain ratios comparing dementia patients to normal controls.

For abbreviations, see legend to Table 1.

\begin{tabular}{lcc}
\hline Ratio & Sensitivity & Specificity \\
\hline $\mathrm{VBr}$ & 44 & 76 \\
$\mathrm{BCr}$ & 39 & 73 \\
$\mathrm{BFr}$ & 32 & 78 \\
$\mathrm{IIIVr}$ & 57 & 84 \\
$\mathrm{SSCr}$ & 48 & 73
\end{tabular}

Table 6 - Sensitivity and specificity of brain ratios (dementia and controls by age groups).

1 - Dementia $x$ age group 1; 2 - Dementia $x$ age group 2; 3 - Dementia $x$ age group 3. For abbreviations, see legend to Table 1 .

\begin{tabular}{lllllllll}
\hline Ratio & \multicolumn{3}{c}{ Sensitivity } & & \multicolumn{3}{c}{ Specificity } \\
\cline { 2 - 3 } & 1 & 2 & 3 & & 1 & 2 & 3 \\
\hline VBr & 44 & 44 & 44 & & 87 & 77 & 56 \\
BCr & 61 & 61 & 61 & & 93 & 54 & 67 \\
BFr & 68 & 68 & 68 & & 80 & 69 & 44 \\
IIIVr & 43 & 43 & 43 & & 93 & 92 & 56 \\
SSCr & 52 & 52 & 52 & & 93 & 62 & 56
\end{tabular}

Table 7 - Analysis of brain measure correlations, individually and in a stepwisestratified way (dementia and controls).

Cognitive measures: Mini-Mental, digit span, word span, famous faces, calculation, abstraction and praxis. Ratios + cognitive measures: combination of brain measures $\left(\mathrm{BFr}, \mathrm{BCr}, \mathrm{IIIVr}\right.$ ) and cognitive tests in a multiple parallel way. $\chi^{2}=$ Chi-square (MantelHaenszel). $\mathrm{OR}(\mathrm{CL})=$ odds ratio and confidence limits. For abbreviations, see legend to Table 1.

\begin{tabular}{lccc}
\hline Measure & $\chi^{2}$ & P value & OR (CL) \\
\hline $\mathrm{VBr}$ & 2.03 & 0.154 & $2.49(0.76-8.34)$ \\
$\mathrm{BFr}$ & 6.66 & 0.009 & $4.40(1.37-14.42)$ \\
$\mathrm{BCr}$ & 6.13 & 0.013 & $4.17(1.30-13.63)$ \\
$\mathrm{IIIVr}$ & 4.40 & 0.035 & $3.88(1.08-14.80)$ \\
$\mathrm{SSCr}$ & 3.11 & 0.077 & $2.91(0.90-9.45)$ \\
$\mathrm{BFr}+\mathrm{BCr}+\mathrm{IIIVr}$ & 5.96 & 0.014 & $6.30(1.35-38.93)$ \\
Cognitive & 36.48 & 0.000 & $80.50(12.4-799.61)$ \\
Ratios + cognitive & 33.56 & 0.000 & $64.17(10.39-628.62)$
\end{tabular}


either SSCr is not influenced by Alzheimer's or multiinfarct dementias, or the changes produced by aging beyond a threshold (age and/or tissue involvement) also include the mesial temporal region. This second hypothesis seems more appropriate and may support the conclusion of Kasahara and coworkers (38) that some changes seemingly representing physiological aging might be promoted by pathologic processes.

Most studies employing CT demonstrate highly significant increases in the distribution of CSF in patients with Alzheimer's disease (39). The regions that showed the greatest difference were the lateral and third ventricles $(40,41)$ and parts of the temporal lobe, such as the CSF areas around the Sylvian fissures and the tips of the temporal horns $(42,43)$. Alzheimer's, but not Huntington's, disease affects the suprasellar cistern (12), suggesting that atrophy of the frontal-temporal basal forebrain areas could be associated with cognitive decline in Alzheimer's disease (12). A technique to estimate CSF volumes from CT scans in Alzheimer patients and normal elderly individuals was evaluated in a longitudinal design (44). The rate of CSF volume showed greater annual increases among Alzheimer's disease patients than among elderly individuals. The enlargement was region specific, with marked annual changes occurring in the ventricular system and the Sylvian fissures. Younger patients showed more rapid progression in the ventricular and frontal sulcal regions than did older patients.

MRI scans may be used to distinguish possible parenchymal abnormalities between different dementia processes. A study carried out on patients with probable Alzheimer's disease, vascular dementia, and normal controls with MRI scans showed significantly more abnormalities (thromboembolic infarctions, confluent white matter, and irregular periventricular hyperintensities) in vascular dementia than in the other subsets. Signal abnormalities on intermediate T2- weighted scans in the uncal-hippocampal or insular cortex were frequent and almost exclusive in Alzheimer's disease. Moderate and severe cortical and ventricular atrophy and a third ventricular to intracranial width ratio higher than $7 \%$ were good discriminators between demented groups and normally aging controls. Selective atrophy measurements, however, failed to separate dementia syndromes, but the authors suggested that MRI has the potential to increase the accuracy of the clinical diagnosis of Alzheimer's disease and vascular dementia (45). Nevertheless, the small number of normal controls could be criticized for these conclusions related to normal aging.

In the present study, cognitive performance among normal controls did not demonstrate the influence of aging. The conclusion that normal function of the brain may be due to better health conditions during the life span and to certain age and/or brain tissue conditions (or amount of neurons or connections) seems relevant. As disease appears, like Alzheimer's or multiinfarct, critical regions for cognitive function are affected progressively to the point of clinical manifestations. The interpretation that brain lesions affect only locally mediated functions ignores a fundamental principle of brain organization: all cognitive tasks are subserved by many areas whose functions are integrated by a complex network of connections. The search for the identification of this point (amount of losses, definition of regions or connections) should continue to help early diagnosis of diseases, to allow strategies to improve prognosis, and/or to modify the course of diseases, especially Alzheimer's. Presently, risk factors are often studied since preventive strategies should be strongly important. There is evidence that the most important determinants for cerebral neurodegenerative changes and cognitive decline during aging are neuronal shrinkage and/or loss, which are accelerated by certain risk factors. The conditions usually assumed as 
risk factors are transient ischemic attacks, hypertension, heart disease, hyperlipidemia, smoking, heavy alcohol consumption, male gender, low educational status, family history of cerebrovascular disease and absence of estrogen replacement therapy among women. Brain degenerative alterations measured by neuroimaging may be premorbid markers for depleted neuronal and synaptic reserves, which predispose to the onset of dementia of both vascular and Alzheimer types (46). Normal subjects at risk for cognitive decline include those with transient ischemic attacks, hypertension and heart disease, because these risk factors accelerate cerebral atrophy, ventricular enlargement, leukoaraiosis, and a decline in cortical perfusion. However, the findings of the present study did not show a significant effect of health or social conditions on brain degeneration or function. The main interpretation of this result is that elderly controls were in very good health, and patients presented either clear probable Alzheimer diagnosis (i.e., exclusion of co-morbidity) or vascular disease.

The analysis of case detection by brain measures and/or cognitive evaluation is the main clinical application of the present findings. Although brain ratios produce interesting data for the purpose of research on pathological mechanisms of dementing illnesses, their clinical impact is not very high. Cognitive evaluation still seems the best method to screen individuals from the community for detection of intellectual decline and dementia, independent of the quality of the health system. For developing countries like Brazil, the cost of investigation with brain imaging should be avoided for screening and initial assessment of dementia, and may be carried out during the further process of diagnosis confirmation. The Agency for Health Care Policy and Research of the US Department of Health and Human Service strongly supports the use of clinical methods (focused history, focused physical examination, and assessments of functional and mental status) for this purpose (35). The mental status is the most critical component of physical examination.

There is evidence suggesting an important role for a measure of the medial temporal lobe as a screening test to detect Alzheimer's disease (47). Whether atrophy of the medial temporal lobe could be detected in life in patients, for whom a diagnosis of Alzheimer's disease was subsequently established by histopathological examination, was the aim of the present study. The minimum width of the medial temporal lobe was measured by temporal-lobe-oriented CT about one year before death. Although limited, there was overlap in the distribution of measures of cases and controls. Two cutoff values $(<0.79$ and $<0.70)$ yielded 5 and $1 \%$ false-positive rates (specificity of 95 and 99\%) and gave expected detection rates (sensitivity) of 92 and $79 \%$. Among nonAlzheimer dementia patients (Alzheimer's disease histopathologically excluded, but not clinically excluded), the ratio was significantly different from that observed in Alzheimer patients, but was not different from that observed in controls. The ratio showed high specificity for Alzheimer's disease and has been suggested to play the role of a 'screening' tool. Screenings are tests of very high sensitivity, because they are expected to identify all real cases in the community even if false-positives are also screened (not so high specificity). This is almost the opposite of what was observed by Jobst and coworkers (47). Furthermore, screening individuals from the community is usually the process of identification of mild cases, which increases the difficulty for this type of test. What will happen for the negative non-Alzheimer demented individuals in the community after the test? Moreover, how do very mild, initial cases of Alzheimer patients perform five or more years before death?

The existence of a test to screen only Alzheimer's disease may be interesting, al- 
though its diagnostic accuracy must be properly evaluated. The use of expensive tests (CT scanning) for first detection of suspected cases, i.e., as a screening test instead of a confirmation test (gold standard), should be extensively studied. Comparison of this method with neuropsychological evaluation may be imperative. The possibility of screening demented individuals from the community by cognitive tests will always be less time and money consuming. Any health professional can be trained for this purpose and be able to correctly apply these instruments.

Another issue of interest is the determination of the place of brain structure alterations related to abnormal cognitive function in non-demented elderly people. Factors such as systemic diseases (hypertension, diabetes, coronary diseases, etc.) and social conditions must be better analyzed in community-based samples especially from various cultures. Definition of their role in determining brain dysfunction is very important for an understanding of the development of abnormal cognitive function in the elderly (differentiation between normal senescence from vascular dementia).

\section{Conclusions}

1) The data suggest diffuse losses of CNS tissue in dementia patients, especially related to the distribution of cerebrospinal fluid; 2 ) the similarities observed in the medial temporal region observed in the aged and dementia groups suggest that the changes produced by aging beyond a threshold (age and/or tissue involvement) may also include this region; 3) dementia patients showed great cognitive impairment compared to controls; 4) cognitive performance did not show the influence of aging among normal controls. With the appearance of disease, like Alzheimer's or multiinfarct, critical regions for cognitive function are affected progressively to the point of clinical manifestations; 5) diagnostic values of brain ratios were low (for IIIVr, sensitivity was $57 \%$ and specificity $84 \%$ ), although interesting for research on pathological mechanisms of dementing illnesses, and 6) cognitive evaluation proved to be the best index for case detection $(87 \%$ sensitivity and $98 \%$ specificity) and seems to be the best method to screen individuals from the community.

\section{References}

1. Evans W (1942). An encephalographic ratio for estimating ventricular enlargement and cerebral atrophy. Archives of Neurology and Psychiatry, 47: 931-937.

2. Aylward EH, Li Q, Habbak QR, Warren A, Pulsifer $M B$, Barta $P E$, J erram $M$ \& Pearlson G (1997). Basal ganglia volume in adults with Down syndrome. Psychiatry Research, 74: 73-82.

3. Cummings J L \& Benson DF (1983). Dementia: A Clinical Approach. Butterworths, Boston.

4. Friedland RP (1993). Epidemiology, education, and the ecology of Alzheimer's disease. Neurology, 43: 246-249.

5. McKhann G, Drachman D, Folstein M, Katzman R, Price D \& Stadlan EM (1984). Clinical diagnosis of Alzheimer's disease: report of NINCDS-ADRDA work group under the auspices of Department of Health and Human Services Task Force on
Alzheimer's disease. Neurology, 34: 939944.

6. Román GS, Tatemichi TK, Erkinjuntti T, Cummings J L, Masdeu JC, Garcia JH, Amaducci L, Orgogozo J M, Brun A \& Hofman A (1993). Vascular dementia: diagnostic criteria for research studies (NINDS-AIREN). Neurology, 43: 250-260.

7. Gustafson L (1992). Clinical classification of dementia conditions. Acta Neurologica Scandinavica, S139: 391-399.

8. Hachinski VC, Iliff LD, Zilkha E, Du Boulay GH, McAllister VL, Marshall J , Russell RW $\&$ Symon L (1975). Cerebral blood flow in dementia. Archives of Neurology, 32: 632637.

9. Blessed $G$, Tomlinson BE \& Roth $M$ (1968). The association between quantitative measures of dementia and senile change in the cerebral gray matter of elderly subjects. British J ournal of Psychia- try, 114: 797-811.

10. Chaves MLF \& Izquierdo I (1992). Differential diagnosis between dementia and depression: a study of efficiency increment. Acta Neurologica Scandinavica, 85: 378-382.

11. Chaves MLF, Bianchin M, Peccin S, Rotta F, J ardim C, Gianiup A \& Eidt L (1993). Chronic use of benzodiazepines and cognitive complaints: a risk factor study. Italian J ournal of Neurological Sciences, 14: 429-435.

12. Aylward EH, Schwartz J, Machlin S \& Pearlson G (1991). Bicaudate ratio as a measure of caudate volume on MR images. American J ournal of Neuroradiology, 12: 1217-1222.

13. Ceitlin L, Santos B, Parisotto L, Zanatta M $\&$ Chaves MLF (1995). Elaboration of word lists in Portuguese with emotional content and their influence on memory func- 
tion in normal subjects. International J ournal of Methods in Psychiatric Research, 5: 195-203.

14. Folstein $M$, Folstein $S \& M c H u g h ~ P$ (1975). Mini-Mental state: a practical method for measuring the cognitive state of patients for the clinician. J ournal of Psychiatric Research, 12: 189-198.

15. Henderson $\mathrm{VW}$, Wendy $\mathrm{M} \&$ Williams BW (1989). Spatial disorientation in Alzheimer's disease. Archives of Neurology, 46: 391-394.

16. Kaplan E, Goodglass H \& Weintraub ST (1976). Boston Naming Test, Experimental Edition. Veterans Administrations Hospital, Boston.

17. Rebok G, Brandt J \& Folstein I (1990). Logitudinal Cognitive Decline in patients with Alzheimer's disease. J ournal of Geriatric Psychology and Neurology, MosbyYear Book, Inc. 3: 91-97.

18. Lombardi C, Bronfman M, Facchini LA, Victora CG, Barros FC, Béria J U \& Teixeira AM (1988). Operacionalização do conceito de classe social em estudos epidemiológicos. Revista de Saúde Pública de São Paulo, 22: 253-265.

19. Aylward $\mathrm{EH}$, Karagiozis $\mathrm{H}$, Pearlson $\mathrm{G} \&$ Folstein MF (1991). Suprasellar cistern measures as a reflection of dementia in Alzheimer's disease but not Huntington's disease. J ournal of Psychiatric Research, 25: 31-47.

20. Ford C \& Winter J (1981). Computerized axial tomograms and dementia in elderly patients. J ournal of Gerontology, 36: 164169.

21. Largen JW, Smith RC, Calderon $M$, Baumgartner R, Lu RB, Schoolar JC \& Ravichandran GK (1984). Abnormalities of brain structure and density in schizophrenia. Biological Psychiatry, 19: 991-1013.

22. Starkstein S, Folstein S, Brandt J, Pearlson G, McDonnell A \& Folstein I (1989). Brain atrophy in Huntington's disease: a CTscan study. Neuroradiology, 31: 156-159.

23. Starkstein S, Brandt J, Folstein S, Strauss $M$, Berthier ML, Pearlson GD, Wong $D$, McDonnell A \& Folstein M (1988). Neuropsychological and neuroradiological correlates in Huntington's disease. J ournal of Neurology, Neurosurgery and Psychiatry, 51: 1259-1263.

24. Woods B \& Wolf J (1983). A reconsideration of the relation of ventricular enlargement to duration of illness in schizophrenia. American J ournal of Psychiatry, 140: 1564-1570.

25. Pearlson GD, Warren A, Starkstein SE, Aylward EH, Kumar AJ, Chase GA \& Folstein MF (1990). Brain atrophy in 18 patients with Down syndrome: a CT study. American J ournal of Neuroradiology, 11: 811-816.

26. Folstein M, Brandt J \& Starkstein S (1990). Cognition in Huntington's disease: characteristics and correlates. In: Franks A, Ironside J , Mindham R, Smith R, Spokes E \& Wilow W (Editors), Function and Dysfunction in the Basal Ganglia. University Press, Manchester, 224-229.

27. LeMay M (1986). VT changes in dementing diseases: a review. American J ournal of Radiology, 147: 963-975.

28. Pearlson G, Kim W, Kubos KL, Moberg PJ , J ayaram G, Bascom M, Chase G, Goldfinger A \& Tune L (1989). Ventriclebrain ratio, computed tomographic density, and brain area in 50 schizophrenics. Archives of General Psychiatry, 46: 690697.

29. Fleiss J L (1986). The Design and Analysis of Clinical Experiments. Wiley, New York.

30. Norusis MJ (1986). Statistical Package for Social Sciences (SPSS)/PC for the IBM PC/XT/AT. SPSS Inc., Chicago.

31. Schlesselman JJ (1982). Case-Control Studies. Oxford University Press, New York.

32. Mantel N \& Haenszel W (1959). Statistical aspects of the analysis of data from retrospective studies of disease. J ournal of the National Cancer Institute, 22: 719-748.

33. Fletcher RH, Fletcher SW \& Wagner EH (1996). Epidemiologia Clínica: Bases da Conduta Médica. Editora Artes Médicas, Porto Alegre.

34. Tombaugh TN \& Mclntyre NJ (1992). The Mini-Mental state examination: a comprehensive review. J ournal of the American Geriatric Society, 40: 922-935.

35. Costa J r PT, Williams TF, Somerfield M, Albert M, Folstein M, Gilman S, Gurland BJ , Gwyther LP, Heyman A, Kaszniak AW, Katz I, Lanska D, Levy LL, Lombardo N \& Storandt M (1996). Recognition and Initial Assessment of Alzheimer's Disease and Related Dementias. Clinical Practice Guideline No. 19. U.S. Department of Health and Human Services, Public Health Service, Agency for Health Care Policy and Research (AHCPR). Rockville, MD, Publication No. 97-0702. November, 56.

36. Baleriaux D, Widelec J \& Aguilera Grijalvo C (1989). The contribution of computerized tomography and MRI in the diagnosis of degenerative dementia. Acta Neurologica Belgica, 89: 156-160.

37. Sandor T, Albert M, Sttaford J \& Harpley S (1988). Use of computerized CT analysis to discriminate between Alzheimer's patients and normal control subjects. Ameri- can J ournal of Neuroradiology, 9: 11811187.

38. Kasahara $H$, Yamada $H$, Tanno $M$, Kobayashi M, Karasawa A, Endo $K$ \& Ushijima S (1995). Magnetic resonance imaging study of the brain in aged volunteers: T2 high intensity lesions and higher order cortical function. Psychiatry and Clinical Neuroscience, 49: 273-279.

39. Sandor T, J olesz F, Tieman J , Kikinis R, J ones K \& Albert M (1992). Comparative analysis of computed tomographic and magnetic resonance imaging scans in Alzheimer's patients and controls. Archives of Neurology, 49: 381-384.

40. Gado M, Hughes CP, Danziger W \& Chi D (1983). Aging, dementia and brain atrophy: a longitudinal computed tomography study. American J ournal of Neuroradiology, 4: 699-702.

41. Albert M, Naeser MA, Levine HL \& Garvey AJ (1984). Ventricular size in patients with presenile dementia of the Alzheimer type. Archives of Neurology, 41: 1258-1263.

42. LeM ay M, Stafford J, Sandor T, Albert M, Haykal H \& Samani A (1986). Statistical assessment of perceptual CT scan ratings in patients with Alzheimer type dementia. J ournal of Computer Assisted Tomography, 10: 802-809.

43. George $A E$, deLeon $M J$, Stylopouos LA, Miller J, Kluger A, Smith G \& Miller DC (1990). CT diagnostic features of Alzheimer's disease: importance of the choroidal/hippocampal fissure complex. American J ournal of Neuroradiology, 11: 101107.

44. Shear PK, Sullivan EV, Mathalon DH, Lim KO, Davis LF, Yesavage J A, Tinklenberg J R \& Pfefferbaum A (1995). Longitudinal volumetric computed tomographic analysis of regional brain changes in normal aging and Alzheimer's disease. Archives of Neurology, 52: 392-402.

45. Schmidt R (1992). Comparison of magnetic resonance imaging in Alzheimer's disease, vascular dementia and normal aging. European Neurology, 32: 164-169.

46. Meyer J S, Terayama Y, Konno S, Akiyama H, Margishvili GM \& Mortel KF (1998). Risk factors for cerebral degenerative changes and dementia. European Neurology, 39 (Suppl 1): 7-16.

47. J obst KA, Smith $A D$, Szatmari $M$, Molyneux A, Esiri ME, King E, Smith A J askowski A, McDonald B \& Wald N (1992). Detection in life of confirmed Alzheimer's disease using a simple measurement of medial temporal lobe atrophy by computed tomography. Lancet, 340 : 1179-1183. 